\title{
Leading Through Conflict with Critical Thinking and Creative Problem-Solving
}

\author{
Thomas Hughes, Joseph Caslin, Cassandra Foss, Adam Larsen, Jennifer Loffer, Katrina Sacco \\ Northern Arizona University
}

\begin{abstract}
This paper draws from the unique perspectives and the guided inquiry of student researchers completing their training and transition into administration. Building on years of prior discussions with similarly positioned students in their culminating principalship course, a small group concerned with the challenges of conflict resolution delved into ways critical thinking and problem-solving skills could benefit their future leadership efforts. Realizing that these skills were no longer mainstays within the literature nor contemporary leadership training, they reflected on conditions they witnessed from their unique vantage point and developed key questions upon which to frame subsequent research. Bringing in limited though relevant literature, and utilizing survey data secured from experienced practitioners, the project ultimately confirmed their perspectives by affirming the need to better create a capacity for critical thinking and problem-solving abilities than is recognized by the professional literature and evidently those responsible for overseeing training practices as well.
\end{abstract}

\section{Introduction}

In the United States the formula for government intrusion and educational compliance is frequently associated with the No Child Left Behind legislation, but in truth it was initiated decades ago. Mandates, standards and assorted teacher-proof classroom practices have long been in place. Still, despite the very visible external domination educators are subjected to, the general public continues to blame teachers and administrators themselves directly for the lack of sustained success experienced by public schools that are essentially only doing what they are being compelled to do $[4,6,7,10]$.

Though educational operations on a whole have become increasingly robotic and a death knell for divergent thinking [7], the day-to-day conflicts facing school leaders are increasingly dynamic, complex and intense $[8,11]$. School leaders, needing to respond to both internal and external constituent complaints, cannot realistically be expected to resolve conflict by implementing mandated initiatives to fidelity. Added to this, administrators may increasingly feel as though they lack the clear direction and full support needed to effectively resolve complex questions. With one hand literally tied behind their back by overriding accountability priorities, school leaders arguably have to wonder if they are truly expected to make a difference, and who it is that they are really answering to. Future administrators in training consistently do.

\section{Unique Vantage Point}

Though the negative side effects of overcompliance have been documented $[4,6,7,10]$ professional literature on a whole does not direct much attention to the perspective just introduced, and especially not to the topics of conflict resolution or problem solving. Conducting a meaningful literature review on critical thinking pushes a researcher back to the 1970s and 1980 s and a time before schools were so thoroughly dominated.

More recently, during the summer of 2019, the website [2] for the American Educational Research Association (AERA) removed SIG 23, which was the special interest group dealing with conflict resolution, from its published list of SIGs. The need to solve problems and address conflict is only growing in frequency, intensity and complexity $7[8,11]$. Despite this, SIG 23 is no longer a focus within the very organization that prides itself on being the clearinghouse of educational research from America - if not actually even around the world.

While the literature may be lacking on the subject of resolving conflict through critical thinking and problem solving, students completing the final culminating course in their school leadership training touch on it during every session. These professionals hold a unique vantagepoint. Still primarily situated in the classroom, many are wrestling with the idealism that prompted their journey into administration, and also the increasingly grim realities they are recognizing by watching others transition into leadership ahead of them. It is common 
for these students to openly question how they will become the leader they set out to be [9], especially as they contend with complex challenges and perspectives they have not been trained for.

\section{Conceptual Origins}

It is difficult to find anyone in education who is more intently invested in both the classroom and the critically supportive role of building leadership, than a future administrator in training. Graduate students who are completing their culminating class in the principalship have typically had a heightened sensitivity to the vitally important mission they are preparing for and its critical impact on teacher and student success. Much like those before them, and others poised to follow in their own training, the future leaders who engaged in this project regularly voiced concerns about being effective problem-solvers. In addition to attempting to articulate their perceptions related to these challenges, this group actively sought to confirm their perspectives with hard data.

Part of their collective concern centered on their developing skill set. Another part of their apprehension had to do with their perceptions of the competing demands and mixed supports that they encountered in education. Keenly aware of expectations surrounding compliance and accountability, most were not certain about there being genuine and enduring support for critical thinking or innovation. Many of the group were not certain which stakeholders in education were truly looking for effective leadership as opposed to those merely interested in maintaining the status quo. Finally, everyone expressed concerns about their individual skill set. There are often stark differences between effective classroom problem-solving methods and approaches employed by school leaders attempting to provide effective and equitable leadership to teachers, parents and the community they serve.

One of the favorite quotes shared in the principalship course was "Choose to engage and focus on those strategies that will help you crawl out-of-the-box effectively without blowing it up at once" [12]. Though there is not much additional recent literature that backed the importance of their perceptions and their focus, Bettez and Hytten [3] articulated the need for developing critical thinking abilities and problemsolving abilities. In addition, Alvoid and Black [1] indicated there is a critical need for school administrators to regain the freedom and ability to return to a practice of thinking out-of-the-box, when conditions warrant it.

Working from their own insights along with the limited available literature that aligned with their perceptions and concerns, the following general guiding questions were developed with the research group from the Principalship course. These questions were eventually refined for inclusion in a planned survey including and more broadly examining additional possible training gaps in other important leadership skill areas.

- Leadership Demand: In contrast to status quo management practices which are often exhibited, who is truly looking for effective leadership from their school administrators?

- Leadership Direction: Are current pressures and expectations creating a climate of compliance or signaling a need for more creativity and innovation from principals and classroom teachers?

- Leadership Training: Needing to deal with increasingly complex challenges and conflict, how well are administrators trained in the area of creative problem-solving and critical thinking skills?

\section{Methods}

The source of information for this study was a sample of 127 Arizona school principals who agreed to participate in a survey examining potential administrator training gaps. This represents a response rate of approximately 20 percent. Considering association directors often decline to cooperate with survey administration as they indicate principals are too busy to complete surveys, 127 responses from Arizona was highly valued and appreciated.

The referenced survey focused on multiple administrator preparation questions beyond those developed for this project. Questions derived from the graduate student inquiry focused on 1 . Who principals felt they were most accountable to, and 2. Whether they felt they were working within more of an innovation mode or locked in a culture of compliance. Linked to these were questions exploring 3. The importance of problem-solving skills along with 4 . The availability of training during their graduate program. Finally, the remaining two questions focused on 5. Rating currently available professional development offerings and 6 . Identifying the best future contexts for professional development and graduate coursework dedicated to this topic. Results from the principal survey carried out in Arizona are offered next, and are represented as they relate to Leadership Demand, Leadership Direction, and Leadership Training. 


\section{Findings}

Results from administrator responses are presented next. They are organized the same way the graduate students identified questions, with the final question having four subparts that were linked to four separate survey questions. Discussion of these results in light of the literature and also including graduate student perceptions and interpretations is found in section 6.0.

\subsection{Leadership Demand}

Principals were asked whether the stronger demand for innovation leadership came from "higher-ups" or from the teachers in their buildings. The graduate students involved in developing the study perceived there to be very strong "demand" for leadership from their teacher peer group. However, administrators did not see it that way. Only $16.6 \%$ of the principals indicated either "somewhat" or "far more" demand from teachers than from higher-ups. In contrast $58.0 \%$ of responding administrators indicated feeling greater expectations coming from above them. Only $25.4 \%$ were neutral about expectations, indicating there were balanced demands.

\subsection{Leadership Direction}

Principals were asked whether ongoing events and expectations prompted them to pursue a course of innovation or one more so aligned with compliance. On a whole, principals who were surveyed indicated greater pressure for compliance at $55.9 \%$. The most frequently chosen individual option was "rapid compliance" coming in at $35.4 \%$ compared to $20.5 \%$ for gradual compliance. In contrast, innovation netted $42.5 \%$ of all responses, with $22.8 \%$ indicating gradual movement in that direction and only $19.7 \%$ seeing rapid movement towards innovation being the norm. The perceptions of the trainees were once again confirmed. There clearly are two very different directions being taken among schools, with only $1.6 \%$ netted for keeping things the same.

\subsection{Leadership Training}

Principals were asked four questions having to do with training as was described within the Methods section. In response to the first of these questions, a total of $88.8 \%$ of principals indicated critical thinking and creative problem-solving was an important skill area. In response to the second training question, only 7 principals $(5.5 \%)$ reported having any in-depth training in critical thinking and problem-solving. One third
(33.1\%) indicated "nothing" in their background and another third (33.9\%) reported receiving occasional mention that related somehow to the concept and skill. The remaining $27.6 \%$ had some assigned work that indirectly related to problem-solving.

Focusing on continuing education in the third question on training, only $1(.8 \%)$ reported receiving comprehensive professional development training at any point. Only $6.3 \%$ felt that the training they received in critical thinking and problem-solving provided them with any level of skills that met their current needs. The remaining ratings indicated professional development was at best loosely related to their needs $(36.2 \%)$, or was the same as what teachers received (13.4\%) and the majority $(43.3 \%)$ reported what was available to them was largely just an afterthought.

The fourth and final question related to training asked for recommendations for future training. Only $3.2 \%$ recommended that it be in the form of continuing education/professional development on an "as needed" basis, with $16 \%$ opting for professional development right away. In all, $80.8 \%$ indicated the need to include this understanding and skill area in the form of graduate training, with $47.2 \%$ indicating the need for in-depth training specific to problem solving.

\section{Discussion}

The topic of this paper and the study it described are largely outside of the scope of the professional literature. In fact, the obvious lack of sustained interest in the subject matter corresponds with the American Educational Research Association (AERA) [2] recently "dropping" the entire broader topic of conflict resolution as a special interest group (SIG 23). Call it all poetic justice, perhaps, as the more common vernacular used for describing the topic of this project is "thinking-out-of-the-box." The very lack of recent and relevant literature on the topic of resolving conflict through creative problem-solving was the critical consideration that prompted both the study and an "outof-the-box" approach for completing it.

Though the professional literature and prominent research leaders may have given up on this topic, a continuous stream of future school leaders completing their studies have regularly voiced awareness of the struggles in this area. We know that school leaders feel pressure to answer more to the top, and that they are divided concerning whether the steps they are taking are innovative or compliant in nature. We also know that school leaders in the field highly value problem-solving skills, but indicate they receive little if any preparation in developing them. The upcoming future leaders, still in training, were the ones to draw attention to this. 
Additional insights provided by the future administrators include the following:

- The high percentage of administrators indicating the importance of meeting expectations from the top may be result of the long-standing power structures in place in public education, as the graduate students (and others before them) were unanimously of the opinion that teachers want authentic leadership for school improvement far more than most people realize, and at least as much as everyone else.

- That only $1.6 \%$ of respondents indicated they were keeping things the "same" or continuing a similar approach to leadership overwhelmingly confirms that there is external stress and critically high need for school leaders to be able to respond to such needs.

- Per our expert educators, implementing mandated programs to fidelity creates many additional problems that can be very challenging to resolve within a culture of compliance. Leaders need to be able to do more than merely insist on complying with fealty or offering to collect data for a future discussion that may not take place. Still, the implementation training they receive rarely offers support much different from this. Effective leaders need to be able to solve problems, and need to feel supported in their efforts to do so.

The team that explored this topic did so to accurately describe their concerns but also to continue to learn and explore ways to improve their own understanding and skills. As one team member reported through the activity, being supported in the effort to more deeply pursue this line of inquiry was the highpoint of their graduate program. Another powerful but less immediate realization for the group was that leaders who are able to think-out-of-the-box provide the "space" the modeling and the reinforcement for their teaching staff and other employee groups to solve problems. The conclusions offered at the end of this paper contain additional insights and recommendations from the transitioning leaders who helped pilot this project.

\section{Conclusion}

Though the literature may not be focused on their topic, future leaders involved in this project were confident that administrators would agree with their perceived need for better developing their critical thinking and creative problem-solving skills. They were also invested in moving beyond talking about need, opting as well to reflect on the key components of effective instruction. Based on their own learning experiences along with their work on this project, the following represent their concluding insights and recommendations on nurturing critical thinking and problem-solving skills in fledgling administrators.

- Graduate students in educational leadership programs need to be provided with targeted coursework directly applicable to their work settings that assists them in understanding and applying "out-of-the-box" thinking and problemsolving skills.

- Graduate students need to be provided with a safe but challenging classroom setting for taking chances and thinking outside-of-the-box.

- Critical thinkers in training need catalysts within their coursework to spur divergent thinking. In their culminating course, Management of the Absurd [5] was a supplementary text that served that purpose to this group of future leaders.

- These graduate students felt a strong need to explore a deeper and more personal understanding of themselves in order to move beyond their longstanding comfort levels.

- Problem-solvers in training should be engaged in collaborative projects, especially those encouraging critical thinking, questioning and brainstorming.

- Future leaders need to realize that thinking outsideof-the-box is not only a skill but a process, and that evaluation of the overall process is more important than the individual product.

- These graduate students thoroughly benefitted from the exchange of personal insights and experiences, and saw increased benefits in engaging and embracing the viewpoints of others as a key to unlocking their own creativity.

- These graduate students highly valued both the opportunity to delve more deeply into the topic of the paper as well as having been provided with many of the supportive conditions outlined above throughout their final "culminating" course.

- These graduate students recognized that their learning and skill development in this critical area needs to be ongoing, and not carried out in isolation.

\section{References}

[1] Alvoid, L, \& Black, L. (2014). The changing role of the principal. Retrieved from Center For American Progress June 11, 2017. The https://www.americanprogress.org/issues/education/rep 
orts/2014/07/01/93015/the-changing-role-of-theprincipal/

[2] American Educational Research Association (2019). About AERA SIGs. Retrieved September 1, 2019 from http://www.aera.net/About-AERA/MemberConstituents/SIGs.

[3] Bettez, S., \& Hytten, K. (2013). Community building in social justice work: A critical approach. Educational Studies, 49: 45-66. American Educational Studies Association ISSN: 0013-1946 print / 1532-6993 online DOI: 10.1080/00131946.2012.749478.

[4] DuFour, R., \& Mattos, M. (2013). How do principals really improve schools? The Principalship, 70(7), 3440.

[5] Farson, B. (1997). Management of the absurd. New York, NY: Simon \& Schuster.

[6] Fullan, M. (2014). The principal: Three keys to maximizing impact. San Francisco, CA:

Jossey-Bass.

[7] Goodwin, B. (2015). The road less traveled: Changing schools from the inside out. Report.

Denver, CO: McREL International.

[8] Hughes, T. (2014). Hiring at risk: Time to ensure hiring really is the most important thing we do. International Journal of Educational Leadership Preparation. NCPEA Press, 8(1), 90-102.

[9] Hughes \& Mouw (2017). Getting more than was registered for: Reciprocal benefits from post-graduate faculty e-mentoring. International Journal for CrossDisciplinary Subjects in Education, Infonomics Society, 8(1), 2944-2953.

[10] Mercer, D. (2016). Who is building the leader: Commentary on educational leadership preparation programs for the future. Educational Considerations, (43)4, 6-10.

[11] Miller, P. (2018). The nature of school leadership: Global practice perspectives. Paul W. Miller. London: Palgrave Macmillan.

[12] Robinson, J. (2012). The $21^{\text {st }}$ Century principal. Retrieved June 11, 2015 from The $21^{\text {st }}$ Century Principal: http://the 21stcenturyprincipal.blogspot. com/2012/12/crawling-out-of-box-5-new-skillsfor.html. 